\title{
Seeing through the Ground: The Potential of Gravity Gradient as a Complementary Technology
}

\author{
N. Metje, ${ }^{1}$ D. N. Chapman, ${ }^{1}$ C. D. F. Rogers, ${ }^{1}$ and K. Bongs ${ }^{2}$ \\ ${ }^{1}$ School of Civil Engineering, College of Engineering and Physical Sciences, University of Birmingham, Edgbaston, \\ Birmingham B15 2TT, UK \\ ${ }^{2}$ School of Physics and Astronomy, College of Engineering and Physical Sciences, University of Birmingham, Edgbaston, \\ Birmingham B15 2TT, UK \\ Correspondence should be addressed to N. Metje, n.metje@bham.ac.uk
}

Received 29 April 2011; Accepted 15 June 2011

Academic Editor: Nagaratnam Sivakugan

Copyright @ 2011 N. Metje et al. This is an open access article distributed under the Creative Commons Attribution License, which permits unrestricted use, distribution, and reproduction in any medium, provided the original work is properly cited.

In the UK there is a huge legacy of buried utility service pipelines and cables beneath our streets and new services, such as fibre optic cables, are being added all the time. Much of this utility network is poorly mapped and recorded. It is therefore important to accurately locate and map these services to aid the installation of new, and repair and maintenance of existing, assets. This will help avoid damage to adjacent services and reduce the direct and social costs associated with finding buried utilities. This paper describes two major UK initiatives-Mapping the Underworld (MTU) and Gravity Gradient Technologies and Opportunities Programme (GG-TOP) - that aim to improve the way that we locate, map, and share information on buried utility services. MTU aims to develop a multisensor device to locate buried services, while GG-TOP aims to develop gravity gradient technology to deliver a (three orders of magnitude) step change in performance.

\section{Introduction}

Most utility services, including electricity, water, gas, and telecommunications, are distributed using buried pipelines or conduits, or via directly buried cables, and the majority of this buried utility infrastructure exists beneath roads. Trenching is usually required whenever they need maintenance, repair, replacement, or extension and this often causes disturbance (and sometimes damage) to other utility services, delays to traffic and/or damage to the environment. Inaccurate location of buried pipes and cables results in far more excavations than would otherwise be necessary, thereby creating a nuisance and increasing the direct costs of maintenance to the service providers, while greatly increasing the costs to others, the most important being the enormous direct cost of traffic delays to business and direct and indirect costs to private motorists. These "social costs" of congestion in the UK alone are estimated to be as high as $\mathfrak{£} 5.5$ billion per annum [1], 5\% ( $\_275$ million) of which is attributed to street works. There are also very considerable environmental "costs" due to traffic congestion, a significant proportion of the damage to the planet due to motor transport deriving from vehicles that are delayed. Nevertheless, utility service providers, who are under enormous pressure from the regulators to improve performance in all sorts of ways and minimize costs to customers, retain the open cut approach and accept the inconvenience of "dry holes" (excavations that miss the target service) as a marginal cost addition. It is important that this attitude changes, but it will only do so when the utility location technologies prove to be reliable, that is, produce accurate and comprehensive plan representations of the buried utility infrastructure with ideally good depth approximations also.

1.1. The UK Heritage. Most of the essential public service infrastructure was installed in the last two hundred years in the UK, to various levels of constructional quality, and with different geographical referencing, depending on age and buried asset type. Worldwide this picture is replicated, albeit that the ages are often not as extreme. Nevertheless, the scope and extent of underground utility and local authority assets worldwide are massive and represent an enormous 
capital investment. For example, the lengths of the different UK assets were reported by Burtwell et al. [2] to be as follows:

(i) $275,000 \mathrm{~km}$ of gas mains;

(ii) $353,000 \mathrm{~km}$ of sewers;

(iii) $396,000 \mathrm{~km}$ of water mains;

(iv) $482,000 \mathrm{~km}$ of electricity cable;

(v) an estimated 2,000,000 $\mathrm{km}$ of telecommunication cables;

(vi) an estimated $500,000 \mathrm{~km}$ of highway drains and surface water sewers.

In addition, there are numerous other services, some of which are largely forgotten in this debate and others are country specific. The UK also has the following:

(i) traffic management cabling (lights, signs, etc.);

(ii) utility service connections to property;

(iii) Network Rail (the national railway infrastructure provider) owns services including signalling, drainage, power and telecommunications, electrification and plant;

(iv) nationally important oil pipelines.

Moreover, much of the UK's urban fabric is very old and dense, the streets are narrow and the utility service infrastructure is largely buried beneath them. Records dating back 200 years are incomplete and of variable quality. Therefore, it is not surprising that the detection of these buried assets is a huge challenge.

1.2. Pressures on Utilities and Society. Utility service providers are faced with the continuing need for high levels of access to an increasingly congested underground environment, with little real knowledge of it and the associated costs of this activity are inevitably large. The UK Government's stated objective of generally available broadband access by 2005 added significantly to the amount of work in roads and footpaths over the last decade and resulted in the installation of services that are very expensive indeed to repair at relatively shallow depths; access to older, deeper utilities must now negotiate another hazard with enormous penalties if third party damage occurs. Moreover, the next thirty years will see gas main replacement programme activities in the UK at higher levels than ever before. This situation, though differing perhaps in detail, is being replicated worldwide.

Growth in the economy, the introduction of competition into the utility services industry and increasing customer demand for essential services has brought with it a greater number of excavations in the streets in order to supply these services. The increase in the number of utilities licensed to lay mains and cables beneath our streets brings with it the increased potential for conflict between the utility service providers, who have statutory rights to use the streets for provision of essential services, the highway authorities and others who maintain them, and those who use the streets for transport purposes (and who are also the recipients of those services). Thus, the situation is complicated further.
As a society, the impact of utility work in roads and footpaths on people and the environment continues to grow, with an increasing recognition of the need to mitigate its effects, evidenced in the UK by Landfill Tax (the costs of disposal of waste from excavations continues to rise), the Aggregate Levy (adding to the cost of new aggregates for backfilling trenches), and the introduction of so-called "congestion tsars" in cities to ease traffic congestion, much of it due to roadworks. More specifically, taxes have been introduced on utility companies who occupy road space to incentivize rapid utility works and ease traffic congestion. For example, lane rental charges and permit schemes were introduced in 2010 and have been trialed in London Boroughs and other Councils in the UK. This will also increase cost pressures if, as planned, they are implemented more widely across the UK. Initial results of the London permit scheme have shown greater collaboration between different utility providers, resulting in more "days saved" in carrying out the work [3] and so the incentives to work more efficiently are having a positive effect. It is evident therefore that there is equally an incentive to those providing the surveying tools needed to make street works more efficient.

1.3. The Consequences of Utility Network Maintenance. The direct cost of trenching and reinstatement work in UK highways for utilities is in excess of $£ 1$ billion per year [4], part of which is attributable to dry holes and damage to third party assets. In 1987 it was estimated that, each year, there were some 75,000 incidents of third party damage to utility equipment, with an associated cost of $£ 25$ million per year [5]. By 2000, the UK water industry alone incurred $£ 15$ million of costs of repairing third party damage [6]. As discussed earlier, growth in the use of fibre optic cable has posed a further risk: one particular incident of damage to a single cable alone cost $£ 0.5$ million to repair [7].

Large though they are, direct costs are significantly less than indirect costs. Those affected by the impact of utility road works include what follows:

(i) highway users, through the cost of congestion, delays and accidents,

(ii) business, through reduced output and turnover due to the delays caused by congestion and disruption of activities in the vicinity of the works,

(iii) local communities, through reduced-or lostaccess to amenities and premises, and overloaded diversionary routes,

(iv) the environment, through damage to trees, increased pollution (noise, fumes and visual), extended use of natural resources, and generation of waste,

(v) third parties, through damage to property,

(vi) highway authorities, who have to repair damaged pavements and deal with the consequences of the compromised life of road structures,

(vii) utility companies, through adverse publicity, abortive costs, and the cost of repairing damage, 
(viii) operatives working in the road exposed to health and safety risks.

As mentioned previously, in total, these indirect costs in the UK are estimated to amount to as much as $\mathfrak{E} 5.5$ billion [1]. Total direct and indirect costs to utilities, industry, society, and government will continue to rise unless better information supplied in the form of utility records and more effective location technologies, both to prove the records information available and discover those utility services that are not recorded, can be made available to those doing the work. Moreover, the rights to open excavation could be questioned if existing legislative measures of controlling road congestion and disruption to the public do not improve the current situation.

This paper will introduce two projects which aim to develop technologies to locate buried assets. If these assets are mapped with 100\% accuracy, the number of dry holes could be reduced considerably (if not removed completely) and utility street works can be carried out far more efficiently. This has the potential to reduce direct costs, social costs and environmental costs, and improve the quality of life in our cities.

\section{The Mapping the Underworld Project (MTU)}

2.1. Initiation and MTU Phase 1. The MTU project (http:// www.mappingtheunderworld.ac.uk/) is a 25-year initiative to improve the way utility companies operate in the street. Although conceived as far back as 1996, MTU was formally initiated at an "IDEAS factory", which was used as an innovative new approach by the UK Engineering and Physical Sciences Research Council (EPSRC) to facilitate multidisciplinary working; in this case to identify complementary projects associated with the location of buried assets. MTU Phase 1, which was coordinated by the first three authors, was active from 2004-2008 and consisted of a $\mathfrak{£} 1.2 \mathrm{~m}$ programme bringing together the universities of Bath, Birmingham, Leeds, Nottingham, Oxford, Sheffield, and Southampton, together with a number of industrial stakeholders. One of the four core projects consisted of a feasibility study to identify suitable sensing technologies, which, when combined, could locate all buried utilities in all ground conditions without the need for probing excavations [8]. In addition, MTU Phase 1 included a project that sought to develop a surface-mounted mapping system, using geoscience techniques, to provide accurate $3 \mathrm{D}$ positional coordinates of the buried infrastructure, even when working in "urban canyons" and represent them in an appropriate 3D electronic mapping system. This work was essential as there is often no clear view of a large section of the sky necessary to obtain an accurate Global Positioning System (GPS) position. This research succeeded in developing a reliable positioning system, integrating GPS and Inertial Navigation Systems (INS) with a precision of approximately one centimeter [9-12].

In the UK, as in many western countries, the utility industry is highly diverse with many private companies operating in any given area. Each of these companies hold their own utility records in a number of formats, the records sometimes being incomplete and/or inaccurate, and sometimes not even in digital form. In order to obtain holistic information on all the buried assets in the ground, the individual records need to be combined. Therefore, MTU Phase 1 also investigated the construction of a unified database of all the location data from the various utility companies, hence providing a network for data sharing (e.g., see $[13,14])$.

The final project of MTU Phase 1 investigated enhanced methods for the detection of buried assets by developing new methods of improving the visibility of underground pipes when surveyed from the ground surface using electromagnetic techniques. A series of "resonant labels" (or RFID tags) were developed. These are relatively simple metallic structures that could be encapsulated within a new pipe prior to installation or attached to an existing pipe that is being repaired $[15,16]$. They provide an effective means of reflecting electromagnetic signals at predetermined frequencies, in much the same way as a bicycle reflector provides enhanced visibility when illuminated by the lights of a car. The RFID tags are regarded as a cost-effective solution and are of particular interest for plastic pipes, which are suggested to be the most challenging type of pipes to be detected by Ground Penetrating Radar (GPR).

All of the above aspects of MTU Phase 1 received followon funding. The VISTA project combined the research into the data integration and GPS positioning aspects of MTU to focus on visualizing integrated information on buried assets to reduce street works (http://www.vistadtiproject.org). The project culminated in field studies aiming to combine automatically data from individual utility records. Largescale tests are currently underway within the London area, that is, the area bounded by the M25 orbital motorway. The RFID tag technology also received follow-on funding from EPSRC under a scheme that aims to bring promising new technological advances arising from the research it funds closer to market.

\subsection{The MTU Multisensor Location Project. The MTU Phase 1 utility location feasibility study demonstrated that all four of the distinctly different geophysical technologies investigated, which were previously used in isolation to locate underground infrastructure, have the potential to be combined in a multisensor device and hence fulfill the vision of MTU, that is, to achieve $100 \%$ detection without the need for proving excavations. This was taken forward by a grant worth $\sim \mathfrak{E 3 . 5}$ million from EPSRC (2008-2012) to research in detail a multisensor device that can detect all buried pipes and cables (termed hereafter buried assets), building on the promising results of the feasibility study and using every possible advantage to see through the ground and focus on the targets. This is undertaken by the universities of Birmingham, Bath, Southampton, and Leeds. The four geophysical technologies that are being researched specifically with regard to their combination in a single, integrated device are GPR, vibroacoustics, passive electromagnetic, and low frequency electromagnetic fields.}


GPR is one of the most common techniques currently utilised to locate buried utilities. Its principles are well established (see [17]), and its limitations are equally well known: it struggles for depth of penetration in saturated clay soils, it requires a good contrast between the target and the material in which it is buried (a void in a gas pipeline can often be more distinct, e.g., than the pipe itself), and it can struggle to see past overlying utilities when seeking deeper targets or distinguish between adjacent utilities in situations where there are congested (cluttered) buried assets. Two approaches are being adopted in the MTU project; the first uses the traditional technique of looking down through the ground, although utilising more advanced ideas such as swept frequency Orthogonal-Frequency Division Multiplexing (OFDM) GPR [18], and the second uses a dual GPR system. The dual system has a transmitter and receiver installed on a robotic device within an existing pipe in the ground, such as a sewer, to "look" outwards, but is combined with a transmitter and receiver at the ground surface so that one-way travel of the signals (pipe to surface, and surface to pipe) can be accommodated. This removes the need for the signals to travel into the ground and back out again as reflections, thereby increasing the effective depth of the survey.

The vibro-acoutstics technique offers a number of advantages to buried utility detection, such as the ability to find plastic pipes, while having the particular advantage of working best in saturated media when GPR struggles due to high attenuation of its signals. Two approaches are being investigated: direct excitation of the buried asset via a manhole or valve that can be used to locate the line of the pipe into the far distance as the waves are transmitted along the pipe and radiate up to the ground surface, where they are detected using an array of geophones or a scanning laser; and excitation of the ground with the aim of detecting the reflected waves from buried pipes using geophones or a laser, which has the potential to locate multiple buried objects $[19,20]$.

The low frequency electromagnetic field technique has been developed from first principles in this research. It has the potential to complement GPR by locating utilities that GPR has difficulty detecting. Examples include small diameter plastic pipes and fibre optic cables, pipes which lie in the blind zone of GPR, and large deep buried assets such as deep sewers, that lie beyond the range of traditional methods [21]. The passive magnetic fields (PMFs) technique utilises the flow of current within a buried AC power cable, which creates an associated oscillating magnetic field that the PMF sensor can detect [22]. Current flow within the power cable can also induce currents within neighbouring utility pipelines or ducts made from conducting materials, such as cast iron, and the PMF has the potential to detect these utilities also.

Two prototype carts have been developed to date. Figure 1 shows one of the prototype carts being pushed along a test site with both a commercial GPR as well as low frequency electromagnetic sensors attached. Furthermore, there are a number of positioning sensors included on the cart to not only give the absolute position of the cart using
GPS, but also relative position of the individual sensors. This is absolutely vital for successful data integration. The other sensors are currently tested separately, with the ultimate goal to combine these on a single cart.

A further important aspect of the project is to investigate techniques for fusion of the data from these various sensors with existing utility records to develop a probability "map" of where the buried services are likely to be. This is essential so that the data are in a form that can be easily understood by the user [23]. Clearly the degree to which this aspect of the research can be advanced is dependent on the outcomes of the work on the sensors. Tests have been conducted over the last 12 months combining the different sensors on two test sites. Initial results of these tests are presented by Royal et al. [24], who also give further details on the latest advances regarding the individual sensing technologies.

In addition, it is well understood that the ground conditions have an important influence on the ability of different sensor techniques to detect buried services. Another aspect of the research is consequently to produce a knowledge-based system (KBS) to aid in the application of the multisensor device and improve survey operational protocols. This KBS will utilise information from a number of sources, such as the geological and geotechnical databases held by the British Geological Survey in the UK. It will also include techniques for converting geotechnical information into geophysical parameters more appropriate for the sensing techniques used to detect the buried services, much of the pioneering research which has been conducted by the MTU team (see [25-28]). This KBS will help utility surveys in a number of ways, for example, it can provide an indication of the likely ground conditions to be expected on a site prior to the survey and hence help the user decide which techniques are likely to work best and also enable the devices to be fine-tuned prior to a survey to maximise their ability to detect the buried services.

As part of the research programme a UK test facility for trialling location technologies and for training operators is also being investigated. A purpose-built facility has been planned and a UK contractor is hoping to build it this year. The facility is based around a number of different bays containing different ground conditions and pipe arrangements. Some bays are being kept simple for testing new technologies and others contain complex arrangements of buried services for more advanced testing and training of personnel. This will provide an ideal testing ground for the multisensor device when it is in its final prototype form and will help to establish site testing protocols such as sequencing of survey technologies.

\section{Gravity Gradient Sensor (GG-TOP Project)}

As indicated above, no single technology will be able to locate all buried assets in all ground conditions. The only way to achieve this goal is by combining a number of different sensing technologies. Although the four technologies being developed under MTU, and being combined on a multisensor cart, are envisaged to have the potential to locate 


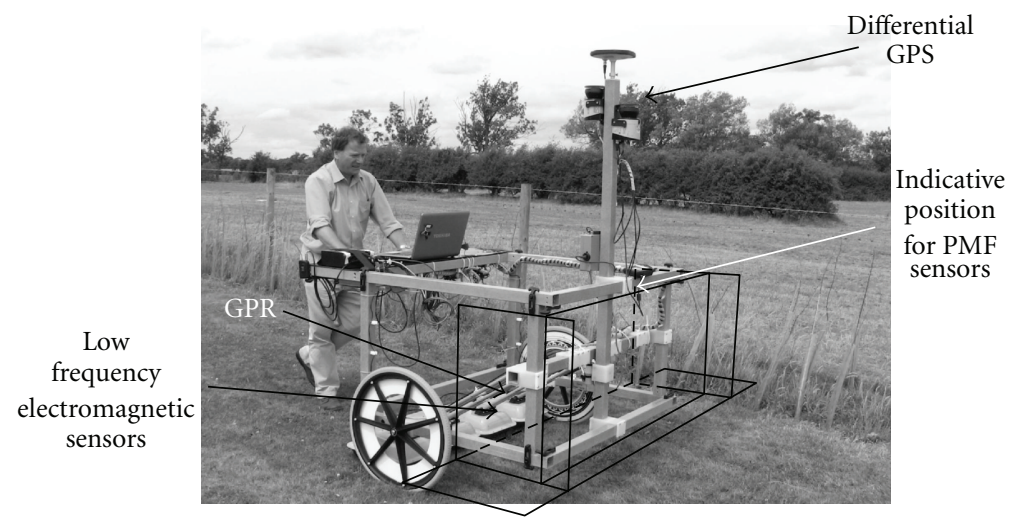

FIGURE 1: Example of one prototype multisensor cart with a commercial GPR, low frequency electromagnetic, and positioning sensors attached. The frame indicates the possible position for the PMF sensors.

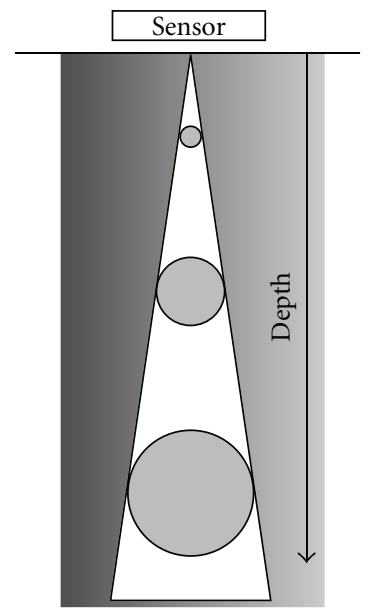

FIGURE 2: Sensitivity cone of a gravity gradient sensor.

all conventionally shallow-buried utilities, it is important to identify additional technologies which could increase the confidence and extend the range of the MTU sensors. GGTOP is such a complementary research programme that aims to explore technologies that seek to deliver a step change in gravity research and gravity gradient mapping (2011-2015). The GG-TOP novel generic technology base will rely on atom interferometry, which, as a disruptive quantum technology, has the potential to exceed conventional gravity gradient sensors by several orders of magnitude in sensitivity and allow new flexible sensor schemes to suppress terrain, geological, and other noise sources, a research need expressed by Difrancesco et al. [29]. These improvements would open up new applications in underground mapping with a potentially enormous impact on industry (construction, buried and surface infrastructure maintenance) and society (by reducing traffic congestion and bringing more sustainable practices to our cities), as well as potentially helping to decipher history via deployment in archaeological settings and advancing fundamental science (testing our model of nature).

Current gravimetric technology has been widely used in the fields of exploration, underwater navigation, and site investigation, but its potential is limited by the unacceptably large measurement time required to deliver anything approaching an acceptable degree of precision. The limitation of current gravity technology is a diameter to depth ratio of approximately unity if time scales acceptable to current industry applications are adopted. The potential of gravity gradient technology as pursued in GG-TOP is to locate small underground features, which will be detected as gravity anomalies, at both shallow and mid-range depths with a diameter to depth ratio of $\ll 1$, for example a $100 \mathrm{~mm}$ object at a depth of up to $10 \mathrm{~m}$, on the same time scale as current technology detects cavities whose dimensions are of the same order of magnitude as their depth (i.e., diameter to depth ratio $=1$ ). This would represent a major step change, which, in principle, presents no obstacle [30], and would serve to complement other surveying technologies. The sensitivity of the sensors can be demonstrated in Figure 2, which shows the sensitivity cone. It indicates that the deeper the target is, the larger it has to be to be detected, while the corollary of this argument is that the sensor can detect small objects close to the surface. The importance of this observation lies in the fundamental approach: the MTU sensors rely on a progressive increase in "power," or "signal magnitude", to see deeper and in increasing the "power" they fail to detect smaller anomalies that lie at small distances below the surface, whereas the gravity gradient sensor has no such "power" limitations; it detects the gravity field that reflects the whole of the buried subsurface. For this reason it is able, for example, to detect a gas filled pipeline that is masked by overlying utility services simply by detecting, very sensitively, the differences in gravitational force at different distances above a reference frame.

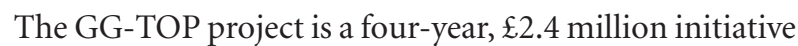
funded by EPSRC which commenced in July 2011. It comprises five work packages (WPs), with the application work package taking a central role (Figure 3). WP1 focuses on the development of the sensor technology, based on the well-established principle of atom interferometry [31] and includes both laboratory and field trials. The aim is to implement and evaluate novel atom interferometric gravity gradiometer schemes to bring about a step change 


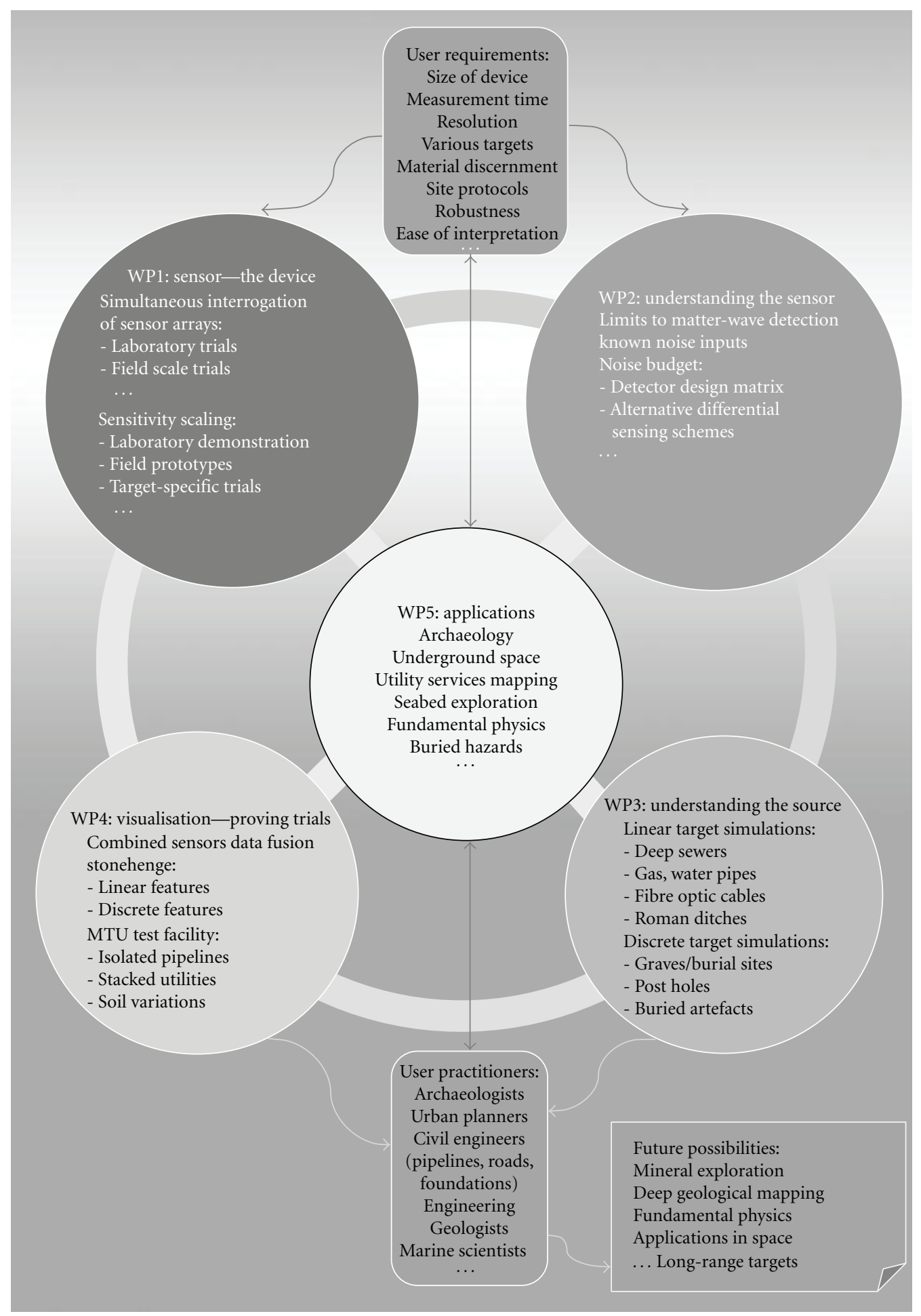

FIGURE 3: Schematic of the GG-TOP project, the interaction between the different work packages, and the potential applications.

in sensitivity and usability. In addition to the laboratory evaluation, a robust technology prototype is to be developed for initial "field/practicality" tests of the new ideas. In parallel, WP2 concentrates on understanding the sensor, in particular the limits to the multiwave detection and the development of a sensor-noise model, building on the work of McGuirk et al. [32]. It will be vital to differentiate the signals received due to underground voids, pipes, and cables, and other buried objects, from those caused by other random noise picked up by the sensor. The aim is to provide a comprehensive MATLAB tool capturing the physics of the sensor to map all conceivable signal and 


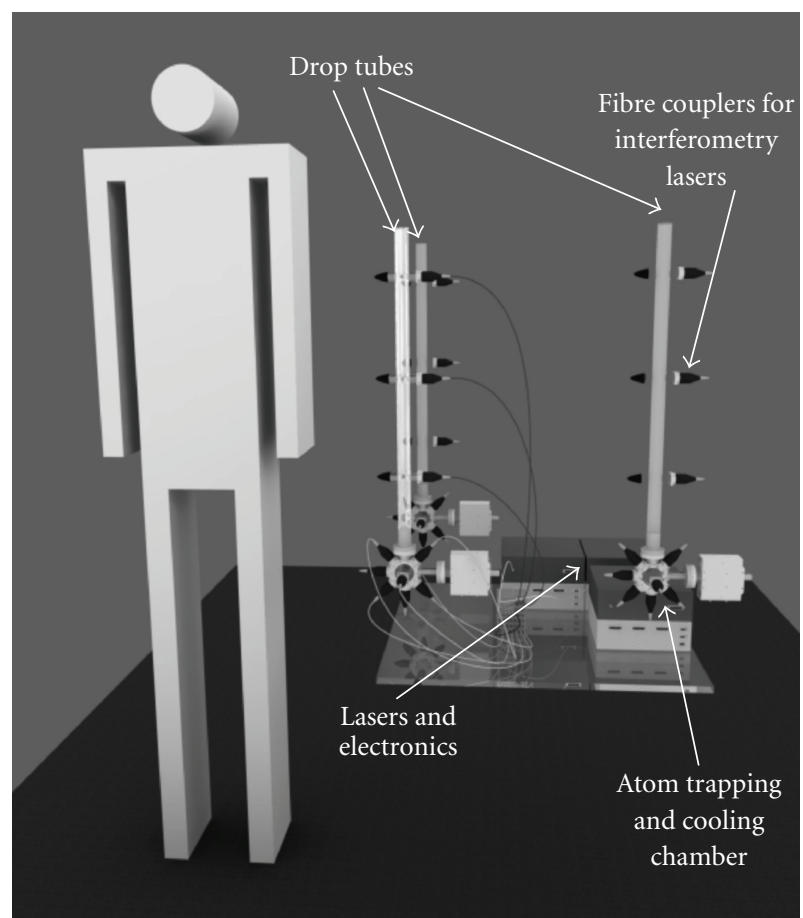

FIGURE 4: Schematic of the potential layout of the gravity gradient sensor. It is envisaged that the sensor will ultimately occupy a volume of $1 \mathrm{~m}^{3}$.

noise inputs to the sensor output. The key input parameters into these two work packages are the user requirements (e.g., the size of the device acceptable for street surveys, the limits on acceptable measurement time to complement other surveying operations, and the resolution needed by those who are required to work on utility services in the street), coupled with data on the target applications in WP5 (i.e. the material properties of the various target assets and their contents).

WP3 focuses on the understanding of the source, incorporating both linear target simulations such as pipes, cables, trenches and ditches, while discrete target simulations will include archaeological features such as graves, post holes and buried artefacts. This work package targets the optimisation of information gained from gravity gradient measurements for the purpose of discriminating multiple overlaid infrastructure assets buried at different depths. In particular, the need for closely spaced arrays of sensors will be examined as a function of ground composition and the required spatial positioning accuracy. WP4 brings the outcomes of WP1, WP2 and WP3 together and concentrates on proof-of-concept trials using both an archaeological site of international importance (Stonehenge in the UK) and the MTU test facilities. Both sites will provide linear and discrete features with the MTU test facilities providing a range of difficulties for buried asset location, with the simplest arrangement containing an isolated pipe and the most complicated a series of stacked and crossing utilities. In addition, the impact of different soils can be tested in the MTU test facility. The aim of this work package is to fuse data from different sensors (including the MTU sensors) and provide an application-specific visual interface between the fundamental technology and the end user. WP5 focuses on the evaluation of the new gravity gradient sensor technology with respect to different applications related to commercial potential (urban mapping, underwater navigation, subsea mapping, and archaeology) and fundamental physics. Importantly, the specifications for a new gravity sensor prototype for the different applications will be derived in this WP. If successful, this project has the potential to reach a large number of practitioners including archaeologists, urban planners, civil engineers, geologists, marine scientists and others. Future possibilities, though not the focus of the current project, include mineral exploitation, deep geological mapping and applications in space, that is, long-range targets.

The novelty of the GG-TOP project is that the gravity gradient is measured at a number of different locations within the sensor, and it is the difference in gravity gradient at these positions that is significant. Figure 4 shows a schematic of the potential layout of the gravity gradient sensor. It is envisaged that the sensor will occupy a volume of approximately $1 \mathrm{~m}^{3}$, thereby making it easily transportable for site surveys. Although likely to be rather large in the initial prototype stage to facilitate wider research explorations, it could still be added to the MTU multisensor cart.

\section{Conclusions}

There is an urgent international need for a combined multisensor device for the complete remote location of buried utility services and other buried infrastructure, as evidenced by the international literature and by the enthusiastic support for the MTU project from UK, European and North American organisations (e.g., the ORFEUS and DETECTINO European projects and the US Transportation Research Board). In the UK alone, the financial impact of the routine use of a comprehensive surveying device is likely to be very considerable indeed, perhaps reaching $\mathfrak{£} 50$ million per annum as the MTU project matures and set to rise as congestion worsens. The argument here is that if

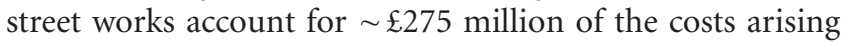
from congestion, then reducing road occupation by $20 \%$ would yield such a saving. The impact on street works of an accurate, comprehensive location technology would be twofold: operations would be far swifter and the enormous number of "dry holes" would be avoided, so road occupancy would be reduced; and a comprehensive underground map of the buried utilities in an area would permit greater use of trenchless technologies. This fact alone justifies the government support, via the UK EPSRC, for the project.

It was demonstrated in MTU Phase 1 that only the combination of different geophysical sensing techniques has the potential to locate all the buried utilities in all ground conditions without the need for proving excavations. This paper has summarised the findings of MTU Phase 1 and has described two current large UK research projects aiming to develop novel sensor technologies. It also demonstrated the 
need to consider user requirements and applications in any such developments. The importance and challenge of data fusion have been highlighted, as the sensors have their own positioning and data format. The exciting approach and wide variety of potential applications, of the gravity gradient sensor provide a valuable potential complementary technology to those being researched in under the MTU initiative. If successful, the gravity gradient sensor would deliver a step change in surveying for geotechnical applications as well as extending the capabilities of utility surveys to far greater depths than currently possible. As such, it is likely to find its use being widely advocated for civil engineering projects of all types and sizes.

\section{Acknowledgments}

The authors wish to thank the UK Engineering and Physical Sciences Research Council for funding the paper (EPSRC Grants EP/F065965/1, EP/I036877/1) and the projects' many industrial partners who are contributing to the paper.

\section{References}

[1] W. McMahon, M. H. Burtwell, and M. Evans, Minimising Street Works Disruption: The Real Costs of Street Works to the Utility Industry and Society (05/WM/12/8), UK Water Industry Research, London, UK, 2005.

[2] M. Burtwell, E. Faragher, D. Neville, C. Overton, C. D. F. Rogers, and T. Woodward, Locating Underground Plant and Equipment-Costed Proposals for a Research Programme (03/WM/12/5), UK Water Industry Research, London, UK, 2004.

[3] I. Hawthorn, Permits One Year on. Presentation at the Utility Street Works 2011 Seminar, 24th February, Institution of Civil Engineers, London, UK, 2011.

[4] Jason Consultants Ltd, "Trenchless construction of pipelines," An unpublished report prepared for TRL Limited, 1992.

[5] D. G. Clow, "Damage to buried plant causes and prevention," in Paper to NJUG Conference, 1987.

[6] L. Sonden, Information Supplied by NJUG to UK Water, Industry Research Ltd, 2002.

[7] K. C. Brady, M. Burtwell, and J. C. Thompson, "Mitigating the disruption caused by utility street works," TRL Report 516, 2001.

[8] N. Metje, P. R. Atkins, M. J. Brennan et al., "Mapping the underworld-state-of-the-art review," Tunnelling and Underground Space Technology, vol. 22, no. 5-6, pp. 568-586, 2007.

[9] G. W. Roberts, X. Meng, A. Taha, and J. P. Montillet, "The location and positioning of buried pipes and cables in built up areas," in Proceedings of the FIG XXIII Congress (FIG '07), 2007.

[10] J. P. Montillet, X. Meng, and G. W. Roberts, "Precise positioning in urban canyons using GPS and GSM," in Proceedings of the of 2nd European Conference on Mobile Government, 2007.

[11] J. P. Montillet, A. Taha, X. Meng, and G. W. Roberts, "Mapping the Underworld; testing GPS and GSM in Urban Canyons," Civil Engineering Surveyor: GIS/GPS Supplement, pp. 4-8.

[12] J. P. Montillet, A. Taha, X. Meng, and G. W. Roberts, "Buried assets: testing GPS and GSM in urban canyons," GPS World, vol. 18, no. 3, pp. 39-43, 2007.

[13] A. R. Beck, G. Fu, A. G. Cohn, B. Bennett, and J. G. Stell, "A framework for utility data integration in the UK," in
Proceedings of the 26th International Symposium of Urban Data Management Society (UDMS '07), V. Coors, M. Rumor, E. M. Fendel, and S. Zlatanova, Eds., pp. 261-276, Taylor and Francis, London, UK, October 2007.

[14] G. Fu and A. G. Cohn, "Semantic integration for mapping the underworld," in Geoinformatics 2008 and Joint Conference on GIS and Built Environment: Geo-Simulation and Virtual GIS Environments, L. Liu, X. Li, K. Liu, X. Zhang, and A. Chen, Eds., vol. 7143 of Proceedings of the SPIE, pp. 1-9, 2008.

[15] J. W. Zhu, T. Hao, C. J. Stevens, and D. J. Edwards, "Optimal design of miniaturized thin-film helical resonators," Applied Physics Letters, vol. 93, no. 23, Article ID 234105, 2008.

[16] T. Hao, H. J. Burd, D. J. Edwards, and C. J. Stevens, "Enhanced detection of buried assets," in Antennas and Propagation Conference (LAPC '08), pp. 249-252, Loughborough, UK, March 2008.

[17] D. J. Daniels, Ground Penetrating Radar. The Institution of Engineering and Technology, London, UK, 2nd edition, 2004.

[18] Q. Zhang, S. Pennock, M. Redfern, and A. Naji, "A novel OFDM based ground penetrating radar," in Proceedings of the 13th Internarional Conference on Ground Penetrating Radar (GPR '10), Lecce, Italy, June 2010.

[19] J. M. Muggleton and M. J. Brennan, "The use of acoustic methods to detect \& locate underground piping systems," in Proceedings of the 9th International Conference on Recent Advances in Structural Dynamics, Southampton, UK, July 2006, paper No. WIP 3.

[20] J. M. Muggleton and M. J. Brennan, "The design and instrumentation of an experimental rig to investigate acoustic methods for the detection and location of underground piping systems," Applied Acoustics, vol. 69, no. 11, pp. 1101-1107, 2008.

[21] K. Y. Foo, P. R. Atkins, A. M. Thomas, and C. D. F. Rogers, "Capacitive-coupled electric-field sensing for urban sub-surface mapping: motivations and practical challenges," in Proceedings of the 1st International Conference on Frontiers in Shallow Subsurface Technology, pp. 157-160, 2010.

[22] P. Wang, P. Lewin, K. Goddard, and S. Swingler, "Design and testing of an induction coil for measuring the magnetic fields of underground power cables," in Proceedings of the IEEE International Symposium on Electrical Insulation (ISEI '10), San Diego, Calif, USA, June 2010.

[23] H. Chen and A. G. Cohn, "Buried utility pipeline mapping based on multiple spatial data sources: a Bayesian data fusion approach," in Proceedings of International Joint Conferences on Artificial Intelligence (IJCAI '11), Barcelona, Spain, 2011.

[24] A. Royal, P. R. Atkins, M. Brennan et al., "Site assessment of multiple sensor approaches for buried utility detection," International Journal of Geophysics. In press.

[25] A. M. Thomas, N. Metje, C. D. F. Rogers, and D. N. Chapman, "Ground penetrating radar interpretation as a function of soil response complexity in utility mapping," in Proceedings of the 11th International Conference on Ground Penetrating Radar (GPR '06), Columbus, Ohio, USA, June 2006.

[26] C. D. F. Rogers, D. N. Chapman, D. Entwisle et al., "Predictive mapping of soil geophysical properties for GPR utility location surveys," in Proceedings of the 5th International Workshop on Advanced Ground Penetrating Radar (IWAGPR '09), pp. 60-67, Granada, Spain, May 2009.

[27] A. M. Thomas, D. N. Chapman, C. D. F. Rogers, and N. Metje, "Electromagnetic properties of the ground: part I-finegrained soils at the liquid limit," Tunnelling and Underground Space Technology, vol. 25, no. 6, pp. 714-722, 2010. 
Advances in Civil Engineering

9

[28] A. M. Thomas, D. N. Chapman, C. D. F. Rogers, and N. Metje, "Electromagnetic properties of the ground: part II -the properties of two selected fine-grained soils," Tunnelling and Underground Space Technology, vol. 25, no. 6, pp. 723-730, 2010.

[29] D. Difrancesco, A. Grierson, D. Kaputa, and T. Meyer, "Gravity gradiometer systems -advances and challenges," Geophysical Prospecting, vol. 57, no. 4, pp. 615-623, 2009.

[30] S. Dimopoulos, P. W. Graham, J. M. Hogan, M. A. Kasevich, and S. Rajendran, "Atomic gravitational wave interferometric sensor," Physical Review D, vol. 78, no. 12, Article ID 122002, 2008.

[31] M. Kasevich and S. Thu, "Measurement of the gravitational acceleration of an atom with a light-pulse atom interferometer," Applied Physics B, vol. 54, no. 5, pp. 321-332, 1992.

[32] J. M. McGuire, G. T. Foster, J. B. Fixler, M. J. Snadden, and M. A. Kasevich, "Sensitive absolute-gravity gradiometry using atom interferometry," Physical Review A, vol. 65, no. 3B, Article ID 033608, 14 pages, 2002. 

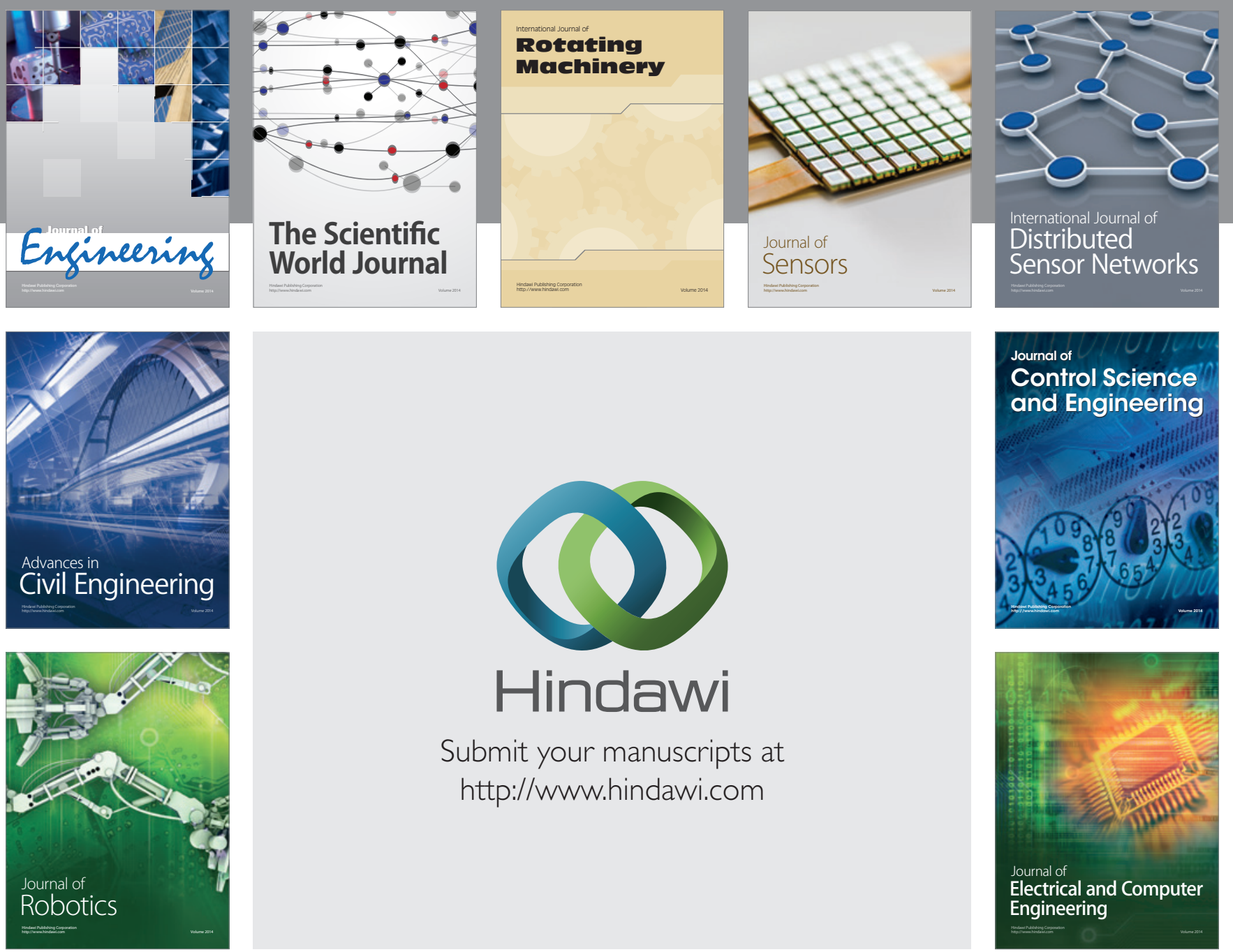

Submit your manuscripts at

http://www.hindawi.com
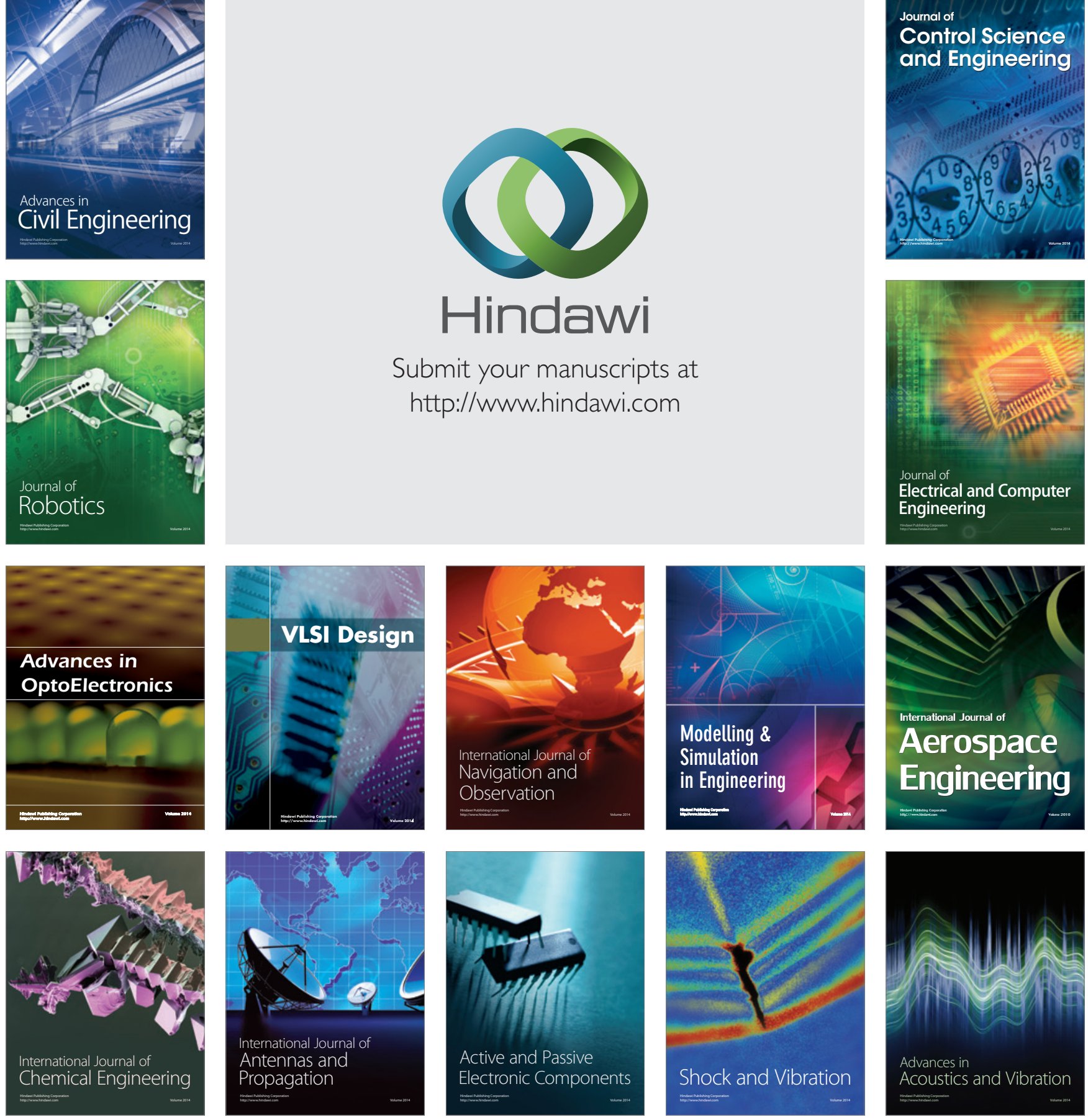